\title{
Thermodynamic and Equilibrium Studies of Dextrin Adsorption on Modified Coal
}

\author{
Okoji Josephine Nkechi ${ }^{1, a *}$, Okolie Justus Ifeanyi ${ }^{2, b}$, \\ Okorocha John Nnaemeka ${ }^{3 c}$
}

\author{
${ }^{1,2,3}$ Department of Chemistry; Federal University of Technology, Owerri Imo State Nigeria \\ aLajoe4real@yahoo.com, bjustusokolie@yahoo.com, ${ }^{\mathrm{C}}$ emybeck@yahoo.com
}

Keywords: Coal, Dextrin, Isotherm, Thermodynamic and Equilibrium

\begin{abstract}
Dextrin produced from cassava was investigated for adsorption on coal during processing. Aluminium ion $\left(\mathrm{Al}^{3+}\right)$ and nitrate ion $\left(\mathrm{NO}_{3}{ }^{-}\right)$were employed for adsorption test to improve coal surfaces. The effect of initial concentration, adsorbent dose and $\mathrm{pH}$ on dextrin adsorption onto modified coal surface was investigated. Studies concerning the adsorption equilibrium and thermodynamics were presented; the equilibrium data was modelled using Langmuir and Freundlich isotherms. The adsorption equilibrium data was well explained by Freundlich isotherm. The percentage removal was found to be $93.75 \%$ and $90.75 \%$ at adsorbent dose of $0.2 \mathrm{~g}$ for both aluminium sulphate coal bituminous (ACB) and aluminium sulphate coal lignite (ACL) respectively. There was a rapid increase in adsorption of dextrin from low $\mathrm{pH}$ of 2 to about $\mathrm{pH}$ of 4 with a plateau region from $\mathrm{pH} 4$ to $\mathrm{pH}$ 6. Adsorption capacity of $61.25 \mathrm{mg} / \mathrm{g}$ and $55.00 \mathrm{mg} / \mathrm{g}$ was achieved at initial concentration of $200 \mathrm{mg} / \mathrm{L}$ for ACB and ACL respectively. For a better interpretation, the nature of the adsorption of dextrin on the prepared coal samples was predicted from thermodynamic point of view by estimating the thermodynamic parameters. The determination of basic thermodynamic parameters: enthalpy of adsorption, Gibb's free energy and entropy of adsorption are important. The negative value of $\Delta \mathrm{G}_{\mathrm{ad}}$ indicates the feasibility and spontaneity of the adsorption process and the magnitude is an indication of the involvement of salt link, electrostatic interaction and hydrophobic bonding in the adsorption.
\end{abstract}

\section{Introduction}

The treatment of fine particles for the recovery of mineral value during processing is an important problem in view of mineral reserves and finer dispersion of value in the remaining ores during coal processing. Solid or liquid separation may be greatly improved by the application of synthetic polymeric flocculants, particularly in coal preparation where flotation, flocculation and coagulation processes are extensively used. This improvement is achieved by bringing dispersed particles together increasing the effective particle size of the solid phase. The stability of the suspension is broken and the liquid phase is released [1].

The surface characteristics of coal may be altered significantly by the adsorption of a surface active agent on the coal surface. Dextrin a starch derivative has found many applications in mineral processing operations such as flotation, flocculation and selective flocculation [2]. All these processes involve the initial adsorption of the polymer at the solid-liquid interface. Adsorption is a technique that is used in many different fields. It involves the accumulation of solute molecules at an interface $[3,4,5]$.

Dextrin and starch have found many applications in mineral processing operations such as flotation which dates back to 1931, when Lange patented starch as a selective depressant in the separation of quartz or hematite and salt type mineral.

A polymer can function as a flocculant only if it is adsorbed on the particle surface and this gives special consideration to the surface chemistry of the mineral $[1,3,6]$. Dextrin is a synthetic watersoluble organic polymer of very high molecular weight used to bridge flocculants and they are strongly adsorbed onto coal particles. They are capable of spanning the gap between the particles. Charge reduction lessens electrical repulsion and enables coagulation to proceed to a further degree. 
Charge is neutralized by the addition of reagents giving rise to charged ions opposite in charge to that carried by the particles, addition of $\mathrm{Al}_{2}\left(\mathrm{SO}_{4}\right)_{3}$, and $\mathrm{NaNO}_{3}$ which give rise to $\mathrm{NO}_{3}{ }^{-}$and $\mathrm{Al}^{3+}$ ions will improve the surface of the coal types in order to obtain the best adsorption properties of dextrin onto coal samples.

\section{Material and Method}

\subsection{Sample collection and preparation}

\section{Adsorbate}

This is the material being adsorbed. Tapioca used in this study was bought from Ihiagwa market, Owerri, Imo state. It was prepared into dextrin to minimize additional cost of treatment processing.

\section{Adsorbent}

This is the solid material being used as the adsorbing phase. Coal samples (brown colour) were obtained from Iyiokwu spring at Okuekpe village in Ebenese Iheoma, Orlu, Imo State and bituminous coal (black colour) were obtained from Onyeama Mine in Enugu, State Nigeria.
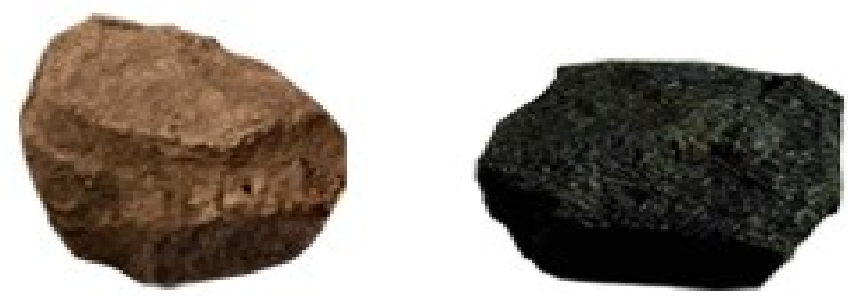

Fig.1. Pictures of Lignite (Brown) and Bituminous (black) Coal

\section{Preparation of the Adsorbent}

The samples were first crushed with hammer and subjected to dry grinding using mortar and pestle. The ground sample was screened through a sieve of $212 \mu \mathrm{m}$ mesh size and stored in a dry plastic until needed.

\section{Preparation of Adsorbate \\ Procedure}

300 grams of tapioca was sun dried until a constant weight was observed. It was ground in a grinder. 50 grams was weighed into a beaker than sprayed with $0.3 \mathrm{~mL}$ of $\mathrm{HCl}$ and vigorously stirred. Then allowed to age for 24 hours before heating for 1 hour at a temperature of $60{ }^{\circ} \mathrm{C}$ while stirring and later cooled in a water-bath at room temperature $[7,8]$.

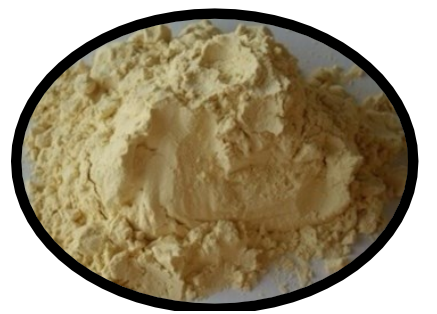

Fig.2. Picture of Prepared Dextrin

\section{Preparation of modified coal}

The coal used in the study was subjected to different surface modification so as to obtain the required surface character. The coal types were treated with $\mathrm{Al}_{2}\left(\mathrm{SO}_{4}\right)_{3}$ and $\mathrm{NaNO}_{3}$ for three hours each. The treated coal surface is designated in this study as: aluminuim sulphate coal bituminous (ACB), aluminium sulphate coal lignite (ACL), sodium nitrate coal bituminous (NCB), sodium nitrate coal lignie (NCL), untreated coal bituminous (UCB), and untreated coal lignite (UCL) and then studied for comparison. Method for coating material was proposed by [5]. 


\section{Procedure}

A solution of $0.02 \mathrm{M}$ of $\mathrm{Al}_{2}\left(\mathrm{SO}_{4}\right)_{3}$ and $\mathrm{NaNO}_{3}$ was prepared by dissolving $6.3 \mathrm{~g}$ and $1.3 \mathrm{~g}$ of $\mathrm{Al}_{2}\left(\mathrm{SO}_{4}\right)_{3}$ and $\mathrm{NaNO}_{3}$ respectively with distilled water in $1000 \mathrm{ml}$ volumetric flask and made up to mark and homogenized respectively. $20 \mathrm{~g}$ of each coal sample (lignite and bituminous) were weighed into $250 \mathrm{ml}$ flask respectively and $200 \mathrm{ml}$ of each prepared solution was added to it respectively. The coal samples was stirred then allowed to stand for three hours after which it was filtered and dried in an oven at $109.8{ }^{\circ} \mathrm{C}$ to a constant weight then cooled in a water bath. The modified coal samples were put in a dried plastic bag and stored in a desiccator until needed for use.

\section{Preparation of stock solution}

The concentrations of starch in solution were determined by the method developed by [1]. Here, the dextrin solution was prepared by caustization, in this method $20 \mathrm{~mL}$ of distilled water was added to $2 \mathrm{~g}$ of dextrin powder to produce a thick paste. The paste was added to approximately $100 \mathrm{~mL}$ of boiling distilled water and mixed thorough. The solution was then added to $1000 \mathrm{~mL}$ volumetric flask. $25 \mathrm{~g}$ of $\mathrm{KOH}$ was added to it and brought to the mark with distilled water. The suspension was shaken, and the resultant solution was homogenised. Dilute starch samples was prepared from the stock solution with $25 \mathrm{~g}$ of $\mathrm{KOH}$. The solution was then cooled to room temperature prior to making the dilute solutions. Fresh starch solutions were prepared each day to minimize the effect of microbial degradation $[4,3,5]$.

\section{Preparation of the solution for the calibration curve}

The batch biosorption test on the adsorption of dextrin by coal was studied, at a known concentration of $25-200 \mathrm{mg} / \mathrm{L}$. Each concentration of the starch in solution was determined by the method developed by [1]. The stock solution was diluted as required to obtain different concentration of dextrin solution. Here, dilute dextrin samples were prepared from the stock solution of $25 \mathrm{~g}$ causticised dextrin as required. $2 \mathrm{~mL}$ of each of these known concentrations above was taken and added into a test tube using a pipette and $1 \mathrm{~mL}$ of $8 \% \mathrm{w} / \mathrm{w}$ phenol diluted with distilled water was added. Then $5 \mathrm{~mL}$ of concentrated tetraoxosulphate (VI) acid was added rapidly and cautiously, the stream of the acid being directed against the liquid surface in the test tube to obtain homogenized solution. The test tube was allowed to stand for 10 minutes after which they were shaken and placed in a cold water bath to cool. The absorbance of the solution in each test tube was measured using UV-Visible spectrophotometer at wavelength of $490 \mathrm{~nm}$. Calibration curves of absorbance against dextrin concentration in $\mathrm{mg} / \mathrm{L}$ were prepared to obtain a standard curve. Blank solution was prepared by treating $2 \mathrm{~mL}$ of distilled water with $1 \mathrm{~mL}$ of $8 \%$ phenol and $5 \mathrm{~mL}$ of concentrated tetraoxosulphate (VI) acid. The absorbance was measured using UV spectrometer [1].

\subsection{Adsorption Study}

$100 \mathrm{~mL}$ of aqueous solution of prepared coal samples of different initial concentrations of dextrin at $25{ }^{\circ} \mathrm{C}$ and various $\mathrm{pH}$ values were studied. Simultaneously, an untreated sample of coal (without cation or anion) at the same experimental conditions was studied. All the experiments were carried out at room temperature and agitating speed of $100 \mathrm{rpm}$ was used.

Adsorption equilibrium isotherms on the six samples of coal were determined using sample dosage of $0.2 \mathrm{~g} / \mathrm{L}$, initial dextrin concentration of $200 \mathrm{mg} / \mathrm{L}$ and at $\mathrm{pH} 6.06$ values.

The $\mathrm{pH}$ values were adjusted with dilute hydrochloric acid and sodium hydroxide solutions by using $\mathrm{pH}$ meter. Langmuir isotherm and Freundlich isotherm were employed, and thermodynamics were investigated.

\section{Dextrin concentration analysis}

The concentration of dextrin was measured prior to checking the initial concentration and following the adsorption test (determination of residual concentration) by means of a spectrophotometer, at wavelength of maximum absorbance of $490 \mathrm{~nm}$. For the adsorption test; Langmuir and Freundlich Isotherms were employed to study the adsorption equilibrium, thermodynamic parameter were used to investigate the nature of the adsorption. 


\section{Result and Discussion}

\subsection{Initial Concentration}

The effect of concentration on the adsorption capacity of dextrin on coal is shown in Fig. 3 and there is a general increase in adsorption of dextrin up to a concentration of $150 \mathrm{mg} / \mathrm{L}$, thereafter the adsorption gradually, remained almost constant. The gradual drop of the curve after $150 \mathrm{mg} / \mathrm{L}$ can be attributed to the saturation of adsorption active sites. Adsorption capacity of $61.25 \mathrm{mg} / \mathrm{g}$ and $55.00 \mathrm{mg} / \mathrm{g}$ was achieved at initial concentration of $200 \mathrm{mg} / \mathrm{L}$ for ACB and ACL respectively. To investigate the effect of the dextrin concentration on the uptake of coal samples, the initial concentration ranging from 25 to $200 \mathrm{mg} / \mathrm{L}$, adsorbent dose of $0.2 \mathrm{~g}$ and at $\mathrm{pH} 6.06$ was used for each adsorption experiment. The adsorption capacity of dextrin depends on the initial concentration of ions which decreased with the increase of initial metal ions concentration. This is due to more adsorption sites available on the adsorbent at low concentrations of the metal ions the final concentration remains constant at initial dextrin concentrations of $150-200 \mathrm{mg} / \mathrm{L}$. This might be due to the fact that the adsorption sites become more saturated as the initial coal concentration are increased and the amount of adsorbent concentration remained constant.

Key:

ACB/L- Bituminous/lignite coal modified with Aluminum

NCB/L- Bituminous/lignite coal modified with Nitrate

UCB/L- Unmodified Bituminous/ Lignite coal.
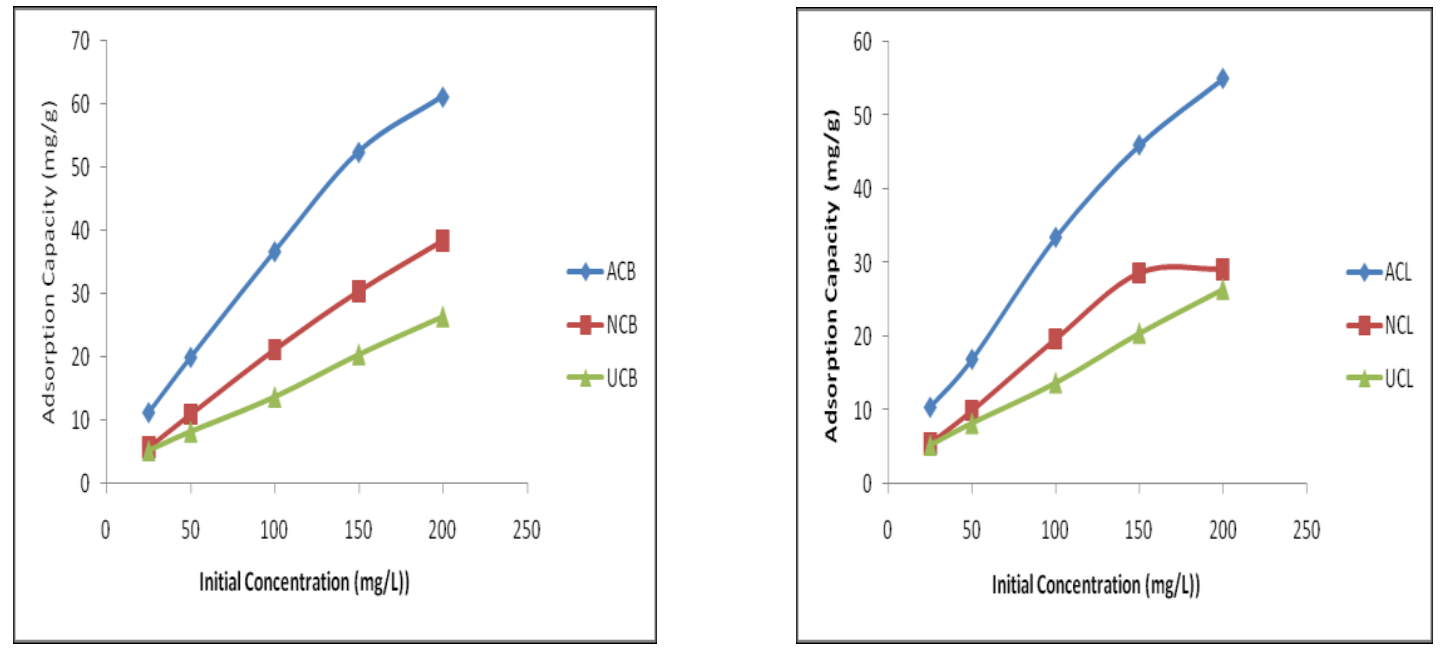

Fig.3. Effect of Concentration on adsorption of dextrin on adsorbents.

\subsection{Effect of Initial $\mathrm{pH}$}

The effect of $\mathrm{pH}$ on the uptake of dextrin by coal is shown in Fig. 4. The initial $\mathrm{pH}$ of adsorption medium is one of the most important parameters affecting the absorption process; the effect of $\mathrm{pH}$ on the absorption of dextrin from aqueous solution by coal is presented in Fig. 4. The initial concentration of the starch used is $200 \mathrm{mg} / \mathrm{L}$.

There was a rapid increase in adsorption of dextrin from $\mathrm{pH} 2$ to about $\mathrm{pH} 4$. A plateau region was observed from $\mathrm{pH} 4$ to $\mathrm{pH} 6$ for dextrin. For $\mathrm{pH}$ values from 4 to just before 12 the amount of dextrin absorbed is independent of $\mathrm{pH}$ for each initial concentration of starch. However for $\mathrm{pH} 6$ above to alkaline, the quantity of dextrin absorbed at equilibrium decreased sharply. This could be associated with the formation of dextrin $(\mathrm{OH})_{2}{ }^{-}$and $(\mathrm{OH})_{4}{ }^{-}$species which might be more attracted to the adsorbent rather than the dextrin. At lower $\mathrm{pH}$, the surface of the adsorbent becomes positively charge as the $\mathrm{OH}^{-}$and other such groups become protonated. This will result in the increase of electrical repulsion between the adsorbent surface and the species to be adsorbed. At $\mathrm{pH} \mathrm{6-7,} \mathrm{the}$ surface of the adsorbent was almost neutral and thus resulting in minimal repulsion between adsorbent and the adsorbate. Negative charge density increases with increase in $\mathrm{pH}$ in coal trend. This observation could be explained in terms of the surface functional groups on coal. It is well 
known that the surface of coal is dominated by oxygenated surface groups such as the phenolic and carboxylic groups. Several studies have shown that the surface chemistry of this coal is determined by these groups although inorganic species also play a role $[9,10]$. In aqueous and basic environments these acids dissociate and the coal particles acquire negative charges, whereas the surface groups are protonated in acidic medium, reducing the negative charge density and the surface may become positively charged in strongly acidic media. The formation of surface charge on coal is depicted by the eq. 1-8 for carboxyl $(\mathrm{COOH})$ and hydroxyl $(\mathrm{OH})$ functional groups. Interaction of dextrin with coal surface ionic sites leads to formation of chemical complexes between dextrin and coal surfaces as shown in eq. 8. This is because oxygenated mineral in aqueous solution form hydroxylated surface. In aqueous solution the acidic proton $\left(\mathrm{H}^{+}\right)$on the coal hydroxyl surface dissociate resulting to charge surface species $[11,12]$.

Dissociation of coal surface

$$
\begin{aligned}
& \mathrm{COOH}_{(\mathrm{S})} \rightleftharpoons \mathrm{COO}_{(\mathrm{S})}+\mathrm{H}^{+}{ }_{(\mathrm{aq})} \\
& \mathrm{COH}_{(\mathrm{S})} \rightleftharpoons \mathrm{CO}_{(\mathrm{S})}^{-}+\mathrm{H}^{+}{ }_{(\mathrm{aq})}
\end{aligned}
$$

Basic solution:

$$
\begin{aligned}
& -\mathrm{COOH}_{(S)}+\mathrm{OH}^{-} \rightarrow-\mathrm{COO}_{(S)}^{-}+\mathrm{H}_{2} \mathrm{O}_{(L)} \\
& -\mathrm{COOH}_{(S)}+\mathrm{H}^{+} \rightarrow-\mathrm{COOH}_{2(S)}^{+} \\
& -\mathrm{COH}_{(S)}+\mathrm{H}^{+} \rightarrow-\mathrm{COH}_{2}^{+}
\end{aligned}
$$

Treated with ionic species

$$
\begin{aligned}
& -\mathrm{MOOH}_{(s)}+H_{(a q)}^{+} \rightleftharpoons-\mathrm{MOOH}_{2(s)}^{+} \\
& -\mathrm{MOH}_{(s)}+\mathrm{OH}_{(a q)}^{-} \rightleftharpoons-\mathrm{MO}_{(s)}^{-}+H_{2} \mathrm{O}_{(L)}
\end{aligned}
$$

\section{Simplified Mechanism of Adsorption}

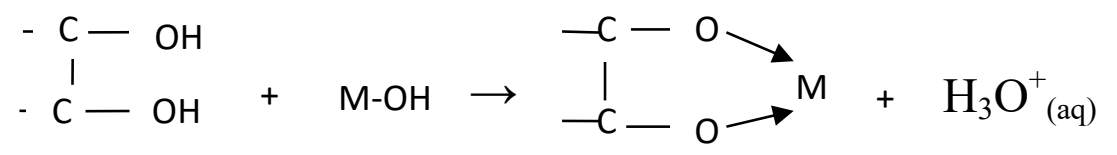

\section{Dextrin modified coal surface}

where: (s) Designate the coal surface; (M) Designate ionic specie $\mathrm{Al}^{+3}$ or $\mathrm{NO}^{-}$; (aq) Designate aqueous solution.

The adsorption of dextrin on coal surface occurs through the mechanism on Eq. 8. Adsorption of the six samples is the same from the $\mathrm{pH}$ results and $\mathrm{ACB} / \mathrm{L}$ have better adsorption power and higher densities than NCB/L and UCB/L samples. This could be attributed to the presence of $\mathrm{Al}^{3+}$ on the coal surface which increases the adsorption, indicating the importance of metal ionic site on adsorption process. Aluminium sulphate dissociates from the mineral surface into the solution to form a colloidal solution of aluminium hydroxide molecule (neutral) and positive charged hydroxide ions: $\left(\mathrm{Al}(\mathrm{OH})^{2+}, \mathrm{Al}(\mathrm{OH})_{2}^{+}, \mathrm{Al}(\mathrm{OH})_{3}\right)$ which depend on $\mathrm{pH}$. Though it is acidic in aqueous solution but the hydroxide formation comes after the achievement of equilibrium to a half, so that the solution also contains some free $\mathrm{Al}^{3+}$ ion. The cationic activity of aluminium sulphate solution is dissolved by the positive charged aluminium hydroxide ions, which are aggregated with the aluminium hydroxide molecules giving a positive zeta potential, where the stability and adsorption of the colloidal dispersions occur.

$$
\begin{aligned}
& \mathrm{Al}_{2}\left(\mathrm{SO}_{4}\right)_{3(\mathrm{~S})}+6 \mathrm{H}_{2} \mathrm{O}_{(\mathrm{l})} \rightleftharpoons 2 \mathrm{Al}(\mathrm{OH})_{3(\mathrm{~S})}+3 \mathrm{SO}_{4}^{2-}+6 \mathrm{H}^{+} \\
& 2 \mathrm{Al}(\mathrm{OH})_{3(\mathrm{~s})} \rightarrow 2 \mathrm{Al}^{3+}+2(\mathrm{OH})_{3}^{-} \\
& 2 \mathrm{Al}(\mathrm{OH})_{3(\mathrm{~s})} \rightarrow 2 \mathrm{Al}^{3+}+6(\mathrm{OH})^{-}
\end{aligned}
$$


Presence of charge equally contributes to the adsorption process. The higher the charge the better the adsorption [13]. Coal contain negative charge surface, it is expected that cation would be suitable in order to neutralize its surface and be able to attract polymer to the particle surface though other factors such as chemisorptions hydrophobic bond, hydrogen bond etc might contribute to this.
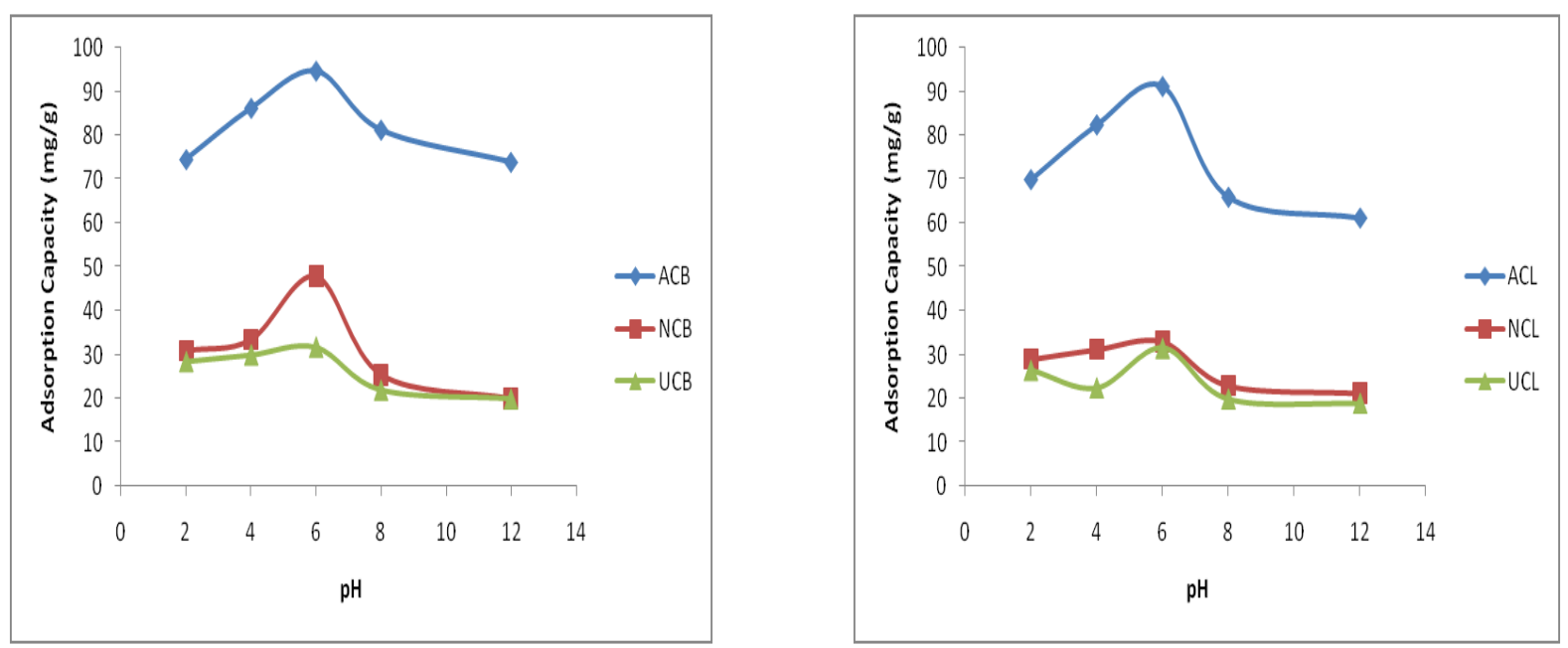

Fig.4. Effect of pH on Dextrin adsorption on adsorbents.

\subsection{Effect of Temperature}

The adsorption of dextrin from aqueous solution at different temperatures was investigated as samples were subjected to temperatures of $30{ }^{\circ} \mathrm{C}$ to $70{ }^{\circ} \mathrm{C}$ as shown in Fig. 5. The adsorption of dextrin has been found to increase with an increase in temperature from $30{ }^{\circ} \mathrm{C}$ to $70{ }^{\circ} \mathrm{C}$. The increase in adsorption capacity of dextrin with temperature indicates an endothermic process. The increase in adsorption with temperature may be attributed to either increase in the number of active surface sites available for adsorption on the adsorbent or adsorbate of adsorbing species and the decrease in the thickness of boundary layer surrounding the adsorbate. At higher temperature the possibility of diffusion of solute within the pore of the adsorbent may be enhanced leading to higher adsorption density since diffusion is an endothermic process, greater adsorption will be observed at high temperature. Thus the diffusion rate of ion in the external mass transport process increases with temperature. The observation of temperature effect of dextrin adsorption on coal therefore confirms that chemical reaction is dominant and this is as a result of fast reaction kinetics of the adsorbate species. This means, particle will travel at a faster rate to the surface to get adsorbed. However, the adsorbed species gain enough energy from temperature of the system and get desorbed at a faster rate than adsorption rate from this study, it was observed that ACB and ACL have the highest adsorption capacity as the temperature increased to $70^{\circ} \mathrm{C}$ from below:
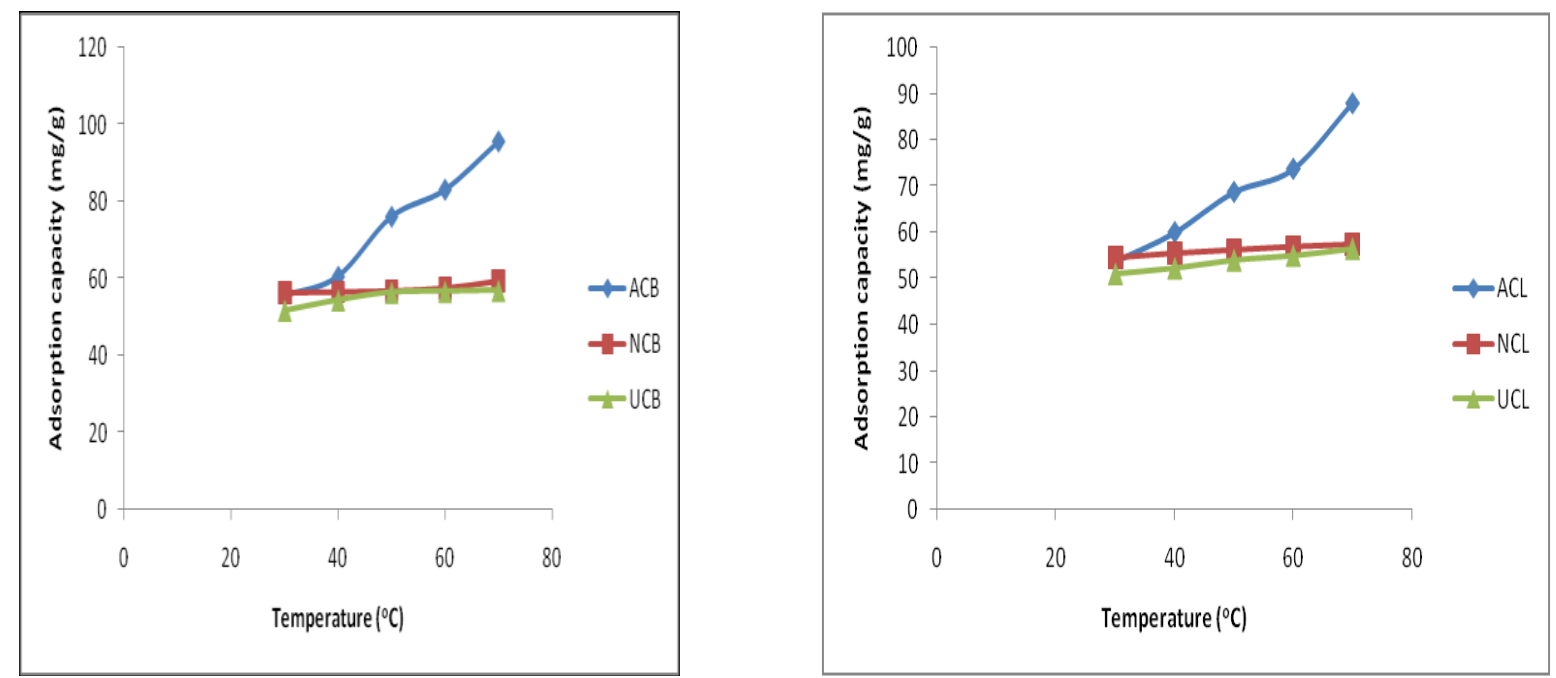

Fig.5. Effect of Temperature on adsorption of dextrin on adsorbents. 


\subsection{Effect of Adsorbent dosage}

The effect of the adsorption of dextrin on dosage was studied by varying amount of adsorbent while keeping $\mathrm{pH}$ at 6.6 , contact time (60 minutes), initial concentration of dextrin solution $(200 \mathrm{mg} / \mathrm{L})$, agitation speed $(100 \mathrm{rpm})$ and temperature of $30{ }^{\circ} \mathrm{C}$ constant. A dosage of the adsorbent has a great influence for adsorption process. As seen in Fig. 6, which shows the effect of adsorbent dosage on dextrin adsorption, the adsorption capacity of dextrin adsorbed on coal samples was decreasing with the increase in adsorbent dosage. The adsorption decreased significantly as dosage increased from $0.2 \mathrm{~g}$ to $1 \mathrm{~g}$ and then tends toward constant at almost $93 \%$. The results indicate that the adsorption capacity of dextrin decreased with increase adsorbent dosage. This implies that the amount of the number of binding site increased which resulted in a split of the flux of dextrin aqueous solution concentration on the surface area of dextrin [10]. This decrease may be described by the electrostatic interaction and interference of binding site which have an influence to reduce adsorbent density [14].
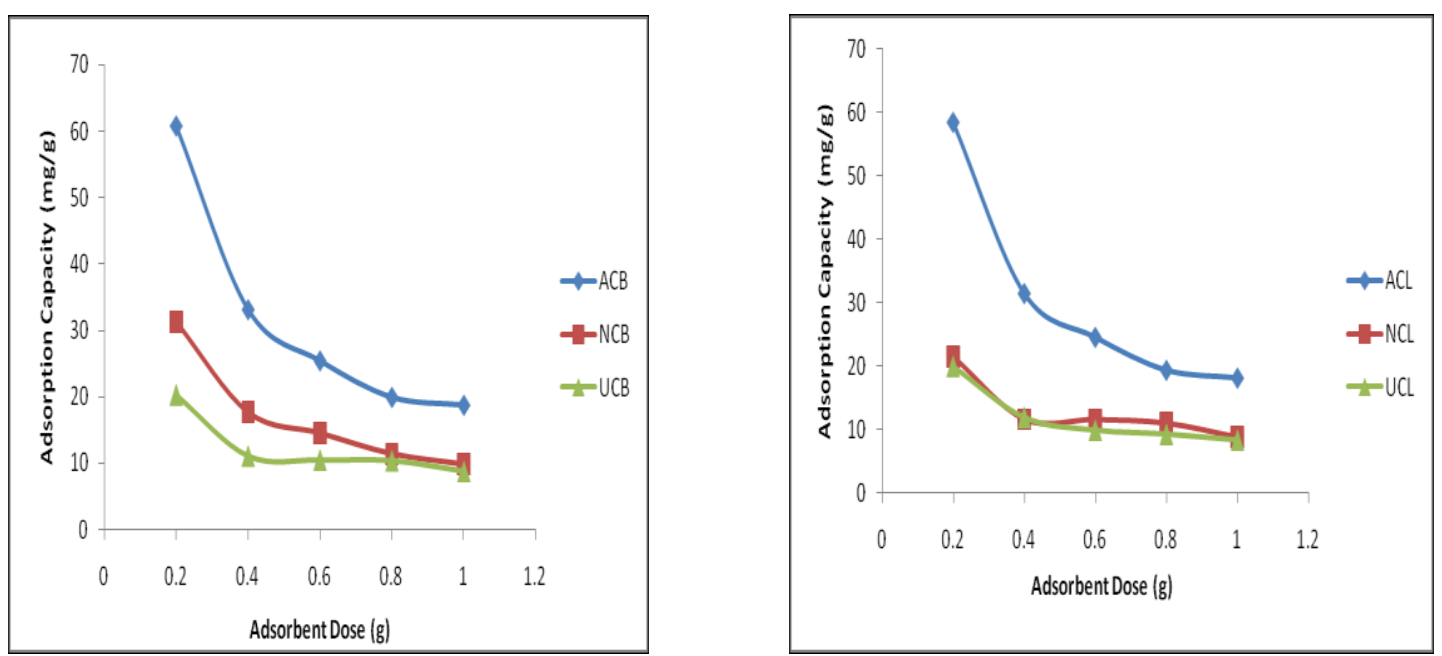

Fig.6. Effect of Adsorbent Dosage on adsorbents

\subsection{Adsorption Equilibrium Study}

Isotherm explains the interaction between adsorbate and adsorbent and is important for the design of adsorption processes. In this work two isotherms were applied to investigate the adsorption process of dextrin on prepared coal samples at different conditions of process parameters. Adsorption equilibrium is established when the amount of solute being adsorbed onto the adsorbent is equal to the amount being desorbed [15]. The equilibrium adsorption isotherms were depicted by plotting solid phase concentration $\left(\mathrm{q}_{\mathrm{e}}\right)$ against liquid phase concentration $\left(\mathrm{C}_{\mathrm{e}}\right)$ of solute.

\section{Langmuir Isotherm}

The Langmuir isotherm is applicable to homogeneous sorption where the sorption of each sorbate molecule on to the surface has equal sorption activation: [16]

$$
\mathrm{q}_{\mathrm{e}}=1+\frac{\mathrm{k}_{\mathrm{L}} \mathrm{C}_{\mathrm{e}}}{\mathrm{Q}_{\max } \mathrm{C}_{\mathrm{e}}}
$$

where $q_{\mathrm{e}}$ is the solid phase sorbate concentration at equilibrium, $K_{\mathrm{L}}$ and $\mathrm{Q}_{\max }$ are the Langmuir isotherm constants.

The linear form of Langmuir equation is given as:

$$
\frac{\mathrm{C}_{\mathrm{e}}}{\mathrm{q}_{\mathrm{e}}}=\frac{1}{\mathrm{Q}_{\max } \mathrm{k}_{\mathrm{L}}}+\frac{\mathrm{C}_{\mathrm{e}}}{\mathrm{Q}_{\max }}
$$

The adsorption data were analyzed according to Eq. 13. The plots of $\mathrm{C}_{\mathrm{e}} / \mathrm{q}_{\mathrm{e}}$ versus $\mathrm{C}_{\mathrm{e}}$ are linear which indicate that the adsorption data fitted reasonably to the Langmuir isotherm according to 
Fig. 7. The constants were evaluated from the slope $\mathrm{Q}_{\max }$ and intercept $1 / \mathrm{Q}_{\max } \mathrm{k}_{\mathrm{L}}$, where $\mathrm{Q}_{\max }$ gives the theoretical monolayer saturation capacity $\mathrm{Q}_{\mathrm{o}}$. The Langmuir constants obtained for all the six adsorbents are summarized in Table 1. The high value of $\mathrm{Q}_{\max }$ obtained for the samples indicate the efficiency of Langmuir model to explain the adsorption process. The adsorption data of other two adsorbents $\mathrm{AC}_{\mathrm{B}}$ and $\mathrm{AC}_{\mathrm{L}}$ were well fitted to the Langmuir equation with reasonably higher $\mathrm{Q}_{\max }$ and low regression coefficients as obtained from Fig. 7 when compared to Freundlich models. The essential characteristics of Langmuir isotherm can be explained in terms of a dimensionless constant separation factor $\left(R_{L}\right)$, which is represented as:

$$
\mathrm{R}_{\mathrm{L}}=1+\frac{1}{\mathrm{k}_{\mathrm{L}} \mathrm{C}_{\mathrm{o}}}
$$

where $\mathrm{C}_{\mathrm{o}}$ and $\mathrm{k}_{\mathrm{L}}$ are the initial concentration and constant related to the affinity of binding sites with the metal ion. The value of $\mathrm{R}_{\mathrm{L}}$, a positive number $\left(0<\mathrm{R}_{\mathrm{L}}<1\right)$, signifies the feasibility of the adsorption process for developed coal samples of initial concentration and temperature studies. The calculated $\mathrm{R}_{\mathrm{L}}$ is given in Table 1 .
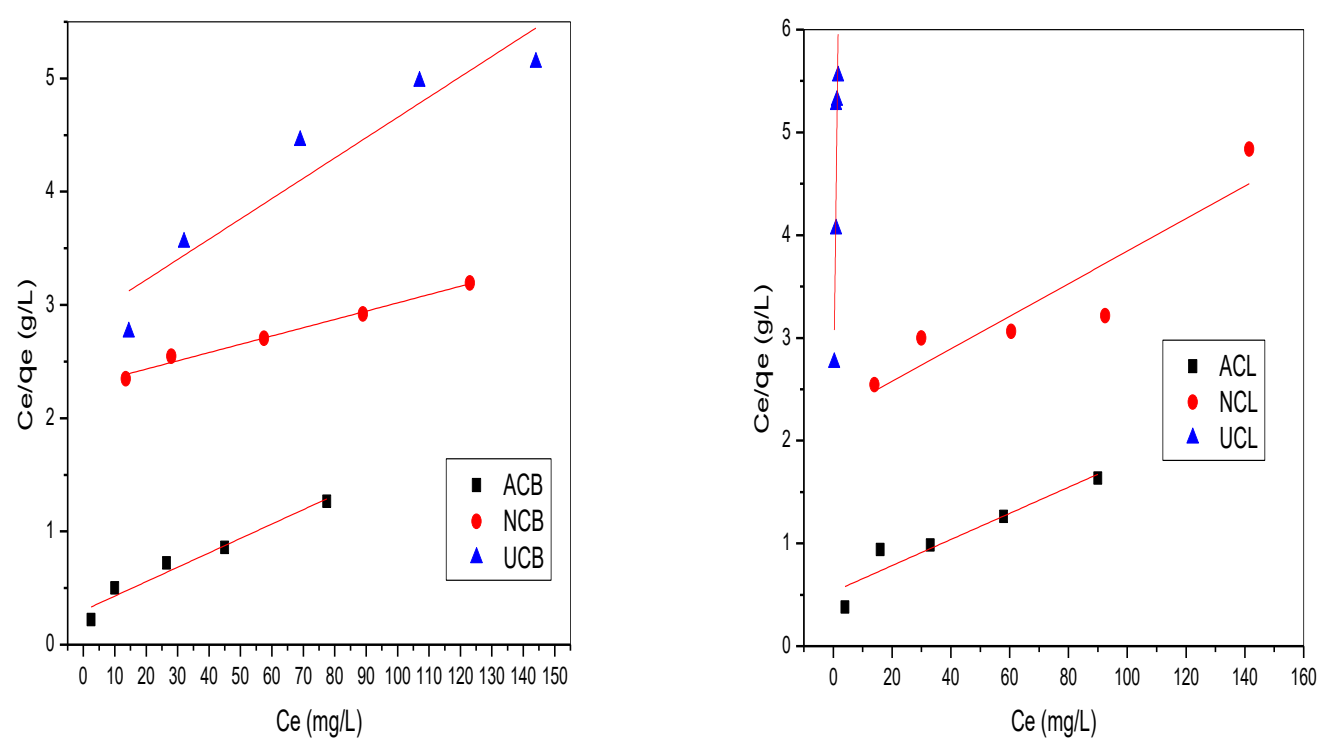

Fig.7. Langmuir adsorption isotherm of adsorbents

\section{Freundlich Isotherm}

Freundlich isotherm is the most important multisite or multilayer adsorption isotherm for heterogeneous surfaces. It is characterized by the heterogeneity factor $1 / \mathrm{n}$ and is represented by the equation:

$$
\text { In } \mathrm{q}_{\mathrm{e}}=\text { In } \mathrm{k}_{\mathrm{F}}+\frac{1}{\mathrm{n}}=\mathrm{C}_{\mathrm{e}}
$$

where, $\mathrm{q}_{\mathrm{e}}$ is the solid phase concentration in equilibrium, $\mathrm{C}_{\mathrm{e}}$ is the liquid phase sorbent concentration at equilibrium, $\mathrm{K}_{\mathrm{F}}$ is the Freundlich constant and $1 / \mathrm{n}$ is the heterogeneity factor. The magnitude of $\mathrm{n}$ gives an indication on the favorability of adsorption. It is generally stated that the values of $\mathrm{n}$ in the range $2-10$ represent good, $1-2$ moderately good, and less than 1 poor adsorption characteristics [16]. The Freundlich isotherm is an empirical equation based on an exponential distribution of adsorption sites and energies. The linear form of Freundlich equation is:

$$
\text { In } \mathrm{q}_{\mathrm{e}}=\operatorname{In} \mathrm{k}_{\mathrm{F}}+\frac{1}{\mathrm{n}} \text { In } \mathrm{C}_{\mathrm{e}}
$$

where, the intercept $\operatorname{lnk}_{\mathrm{F}}$ is a measure of adsorption capacity, and the slope $1 / \mathrm{n}$ is the adsorption intensity. The values of $\mathrm{k}_{\mathrm{F}}$ and $\mathrm{n}$ were calculated from the intercept and slope of the plots $\ln \mathrm{q}_{\mathrm{e}}$ against $\operatorname{lnC}_{\mathrm{e}}$ in Fig. 8. The Freundlich isotherm describes reversible adsorption and is not restricted 
to the formation of monolayer. The isotherms were found to be linear as is evident from correlation coefficients obtained in the range of $0.989-0.969$. The Freundlich isotherm showed a better fit to the adsorption data than Langmuir isotherm suggesting heterogeneous nature of the coal samples. Freundlich sorption isotherm constants were determined for all the samples and are summarized in Table 1. The steepness and curvature of isotherms were obtained from the values of $\mathrm{k}_{\mathrm{F}}$ and $\mathrm{n}$. The value of $k_{F}$ signifies the adsorption intensity and higher $k_{F}$ value and lower $1 / n$ value of $A C B / L$ confirmed the higher adsorption capacity for dextrin as compared to other samples i.e. NCB/L$\mathrm{UCB} / \mathrm{L}$. The obtained $\mathrm{k}$ and $\mathrm{n}$ values of $\mathrm{AC}_{\mathrm{B}}$ and $\mathrm{AC}_{\mathrm{L}}$ are 6.714/1.934 and 4.415/1.783 respectively [18].
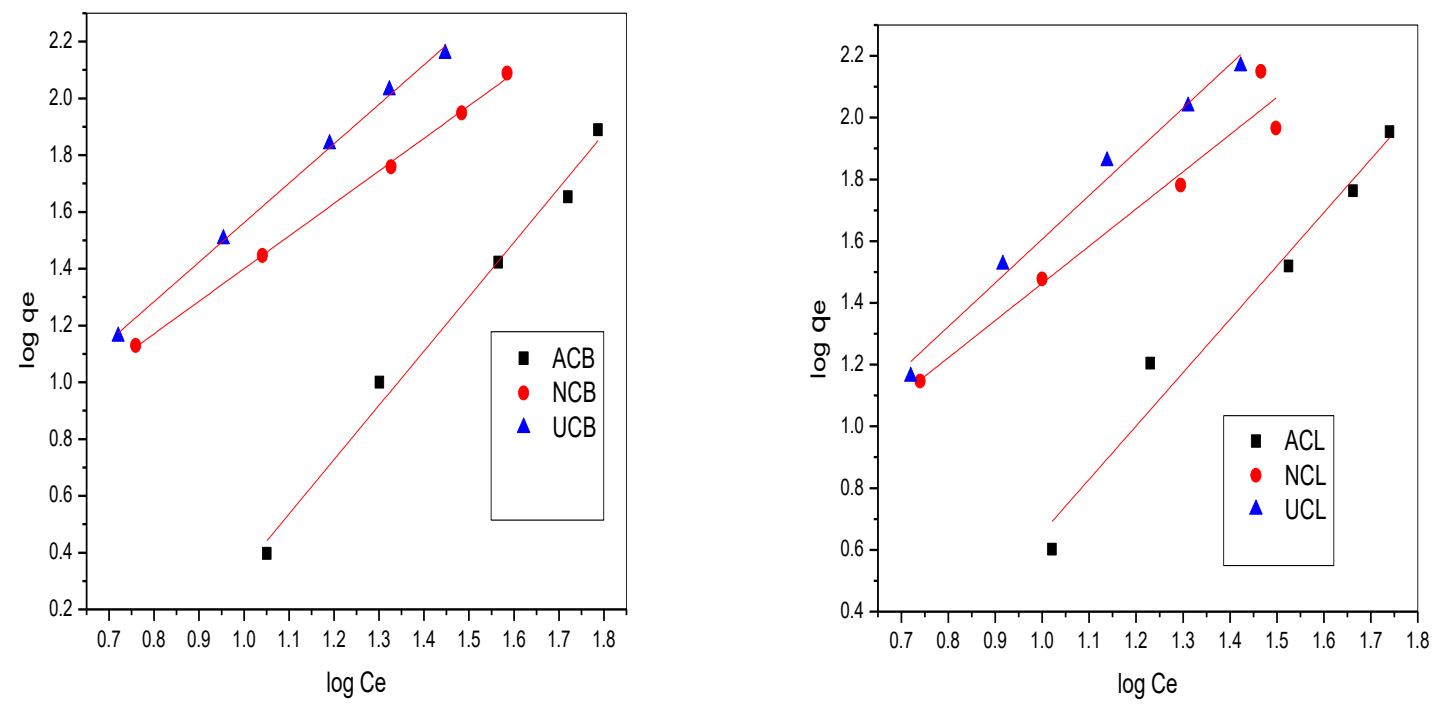

Fig.8. Freundlich adsorption isotherm of adsorbents

Table 1. Langmuir and Freundlish isotherm results

\begin{tabular}{|c|c|c|c|c|c|c|c|}
\hline Sample & \multicolumn{4}{|c|}{ Langmiur } & \multicolumn{3}{|c|}{ Freundlich } \\
\hline & $\begin{array}{c}\mathrm{K}_{\mathrm{L}} \\
(\mathrm{L} / \mathrm{g})\end{array}$ & $\begin{array}{c}\mathrm{Q}_{\max } \\
(\mathrm{mg} / \mathrm{g})\end{array}$ & $\mathrm{R}_{\mathrm{L}}$ & $\mathrm{R}^{2}$ & $\begin{array}{c}\mathrm{K}_{\mathrm{f}} \\
(\mathrm{L} / \mathrm{g})\end{array}$ & $\mathrm{n}$ & $\mathrm{R}^{2}$ \\
\hline $\mathrm{ACB}$ & 0.0398 & 83.33 & 0.259 & 0.959 & 6.714 & 1.934 & 0.989 \\
\hline ACL & 0.0226 & 83.33 & 0.015 & 0.898 & 4.415 & 1.783 & 0.969 \\
\hline NCB & 0.0064 & 76.92 & 0.015 & 0.988 & 0.605 & 1.149 & 0.998 \\
\hline NCL & 0.0066 & 66.66 & 0.015 & 0.847 & 0.732 & 1.285 & 0.970 \\
\hline UCB & 0.0059 & 58.82 & 0.018 & 0.901 & 0.748 & 1.385 & 0.998 \\
\hline UCL & 0.0060 & 52.63 & 0.014 & 0.775 & 0.760 & 1.434 & 0.986 \\
\hline
\end{tabular}

\section{Thermodynamic of Sample Adsorption}

The nature of the adsorption of dextrin on the prepared coal samples was predicted by estimating the thermodynamic parameters. The determination of basic thermodynamic parameters: enthalpy of adsorption, Gibb's free energy and entropy of adsorption is important, it estimates if the process is favourable or not from thermodynamic point of view, it assess the spontaneity of the system and to ascertain the exothermic or endothermic nature of the process. The changes in thermodynamic parameters such as free energy $\left(\Delta \mathrm{G}^{\mathrm{o}}\right)$, enthalpy $\left(\Delta \mathrm{H}^{\mathrm{o}}\right)$ and entropy $\left(\Delta \mathrm{S}^{\mathrm{o}}\right)$ were evaluated from the following equations $[19,20]$ :

$$
\Delta G^{\circ}=-\mathrm{RT} \text { In } \mathrm{k}_{\mathrm{c}}
$$

Where, $\mathrm{k}_{\mathrm{c}}$ is the equilibrium constant and is calculated as:

$$
k_{c}=\frac{C_{A C}}{C_{e}}
$$


$\mathrm{C}_{\mathrm{AC}}=\left(\frac{\mathrm{mg}}{\mathrm{g}}\right)$ and $\mathrm{C}_{\mathrm{e}}=\left(\frac{\mathrm{mg}}{\mathrm{L}}\right)$ are the equilibrium concentrations for solute on the adsorbent and in the solution, respectively. The $K_{c}$ values were used to determine the $\Delta G^{\circ}, \Delta H^{\circ}$ and $\Delta S^{o}$ expressed in terms of the $\Delta \mathrm{H}^{\mathrm{o}}(\mathrm{kJ} / \mathrm{mol})$ and $\Delta \mathrm{S}^{\mathrm{o}}(\mathrm{kJ} / \mathrm{mol})$ as a function of temperature:

$$
\text { In } \mathrm{k}_{\mathrm{c}}=\frac{\Delta \mathrm{H}^{\circ}}{\mathrm{RT}}+\frac{\Delta \mathrm{S}^{\circ}}{\mathrm{R}}
$$

$\Delta \mathrm{H}^{0}$ and $\Delta \mathrm{S}^{0}$ were obtained from the slopes and intercepts of the plots of $\ln \mathrm{k}_{\mathrm{c}}$ against 1/T shown in Fig. 9. The free energy change $\left(\Delta \mathrm{G}^{0}\right)$ indicates the degree of spontaneity of the adsorption process and the negative value reflects a more energetically favorable adsorption. The increase in negative value of $\Delta \mathrm{G}^{\mathrm{o}}$ with increase of temperature showed that the adsorption of dextrin on prepared ACB and ACL samples increased with the rise in temperature in order of 0.554 to -8.726 and -0.377 to $5.675 \mathrm{kJmol}^{-1}$ respectively than other samples. The positive values of $\Delta \mathrm{H}^{\mathrm{o}}$ shown in Table 2 confirmed the endothermic nature of the adsorbents for dextrin adsorption in the studied range $30-$ $70{ }^{\circ} \mathrm{C}$. The negative values of $\Delta \mathrm{S}^{\mathrm{o}}$ confirmed a decrease in randomness of the adsorption process at the solid or solution interface and it followed the order $\mathrm{ACB}>\mathrm{ACL}>\mathrm{NCB}>\mathrm{NCL}>\mathrm{UCB}>\mathrm{UCL}$ [20].
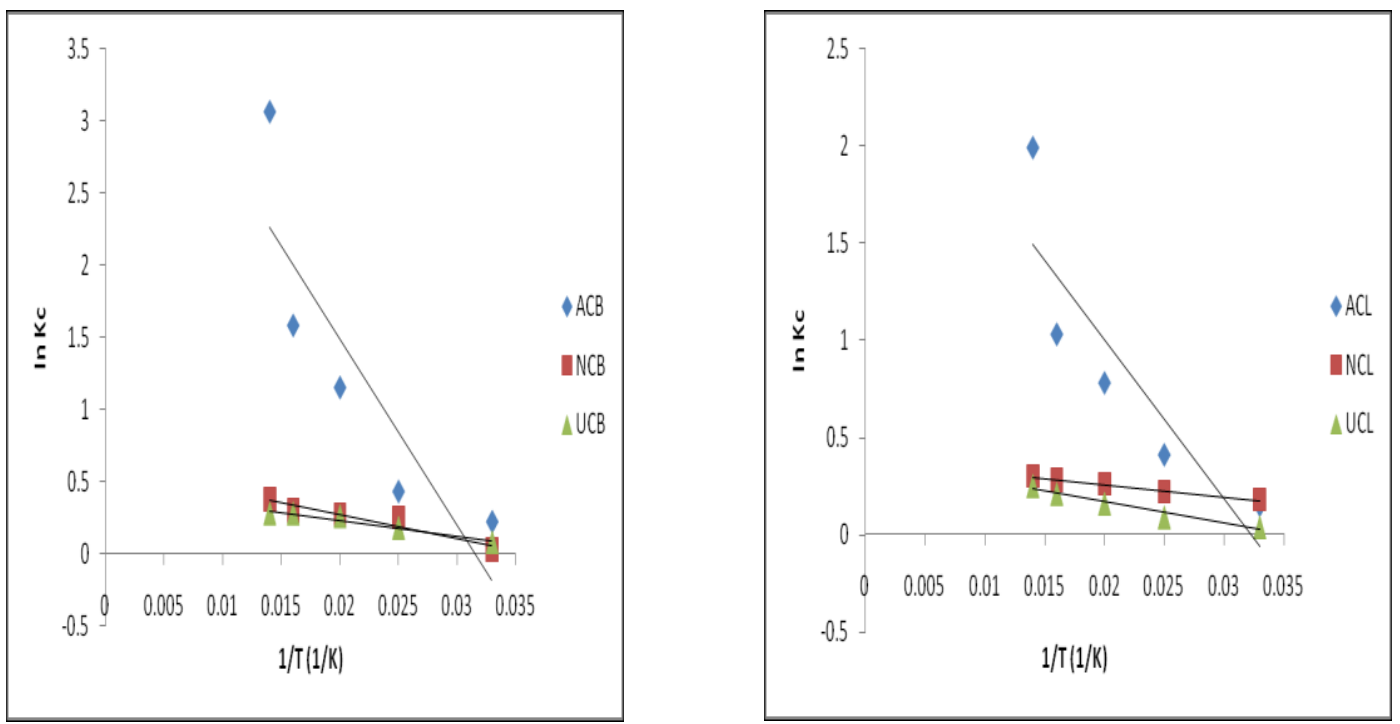

Fig.9. Plot of $\ln$ Kc vs. 1/T for adsorption of dextrin on adsorbents.

Table 2. Thermodynamic parameters for adsorption of dextrin on coal samples.

\begin{tabular}{lccccccc}
\hline Sample & \multicolumn{9}{c}{$\triangle \mathbf{G}(\mathbf{k J} / \mathbf{m o l})$} \\
& $\mathbf{3 0}{ }^{\mathbf{0}} \mathbf{C}$ & $\mathbf{4 0}{ }^{\mathbf{0}} \mathbf{C}$ & $\mathbf{5 0}{ }^{\mathbf{}} \mathbf{C}$ & $\mathbf{6 0}{ }^{\mathbf{}} \mathbf{C}$ & $\mathbf{7 0}{ }^{\mathbf{}} \mathbf{C}$ & $\begin{array}{c}\triangle \mathbf{H} \\
\mathbf{( k J / m o l})\end{array}$ & $\begin{array}{c}\triangle \mathbf{S} \\
(\mathbf{k} / \mathbf{m o l})\end{array}$ \\
\hline ACB & -0.554 & -1.118 & -3.088 & -4.374 & -8.726 & 57.316 & -187.23 \\
ACL & -0.377 & -1.066 & -2.095 & -2.852 & -5.675 & 38.855 & -120.80 \\
NNB & -0.639 & -1.615 & -0.725 & -0.831 & -1.084 & 2.560 & -10.31 \\
NCL & -0.453 & -0.573 & -0.698 & -0.775 & -0.856 & 2.651 & -10.22 \\
UCB & -0.202 & -0.468 & -0.698 & -0.775 & -0.798 & 4.568 & -15.86 \\
UCL & -0.100 & -0.234 & -0.429 & -0.581 & -0.713 & 4.658 & -15.59 \\
\hline
\end{tabular}

\section{Conclusions}

In this work, the ability of dextrin to adsorb on coal surface from aqueous solution was investigated. Studies concerning the adsorption equilibrium were presented and discussed. Experimental results showed that dextrin was effective in aqueous solution when coal surface was coated with $\mathrm{Al}^{3+}$. Equilibrium data obtained was modelled using two isotherms: Langmuir and Freundlich and the equilibrium isotherm were well described by Freundlich equation. The maximum adsorption 
kinetics was well described by the Pseudo second order model equation. The adsorption mechanism was suggested to be complex, consisting of both surface adsorption and pore diffusion. This study proved that dextrin appeared to be more stable adsorbent in solution when the coal surface is modified with $\mathrm{Al}^{3+}$ from $\mathrm{AI}_{2}\left(\mathrm{SO}_{4}\right)_{3}$. It provides a means of adsorption onto the particle surface by electrostatic attraction and makes the polymer to extend and uncoiled due to charge repulsion along the length of the polymer chain, so that the molecule is more nearly linear and can therefore accommodate more particles.

Since dextrin can be locally prepared and is cheap, the result is expected to be economically viable for the adsorption of dextrin on coal surface from aqueous solution. Therefore, locally prepared dextrin can serve as a replacement for currently expensive adsorbates such as silica gel, gum and zeolite during coal processing. Coal is an important rock mineral which is used in production of many things, apart from using it as source of energy [22].

\section{References}

[1] E.O.Oyelude, Comparative study of the adsorption of Maize starch and Cassava starch onto Heamatite, J. App. Tech. in Envi. Sanitation. 3 (2011) 335-241.

[2] J.S. Laskowski, Q. Liu, N.J. Bolin, Polysaccharides in Flotation of Sulphides. Part I. Adsorption of Polysaccharides onto Mineral Surfaces, Int. Journal of Min. Proc. 33 (1991) 223-234.

[3] O.I. Liu, The Role of mineral surface composition and hydrophobicity in mineral interactions, Ph.D. Thesis, U. of British Columb, 1988.

[4] Q. Liu, J.S. Laskowski, The Interaction between Dextrin and Metal Hydroxides in Aqueous Solutions, Journal of Colloid Interface Sci. 130 (1989) 101-111.

[5] Q. Liu, J.S. Laskowski, The Role of Metal Hydroxides at Mineral Surfaces in Dextrin Adsorption Studies on Modified Quartz Samples, Int. Journal of Min Proc. 26 (1989) 29-316.

[6] Q. Liu,Y. Zhang, J.S. Laskowski, The adsorption of polysaccharides onto mineral surfaces: an acid/base interaction, International Journal of Mineral Processing. 60(3) (2000) 229-245.

[7] O.S. Azeez, Production of dextrin from cassava starch, B.Sc. Thesis, Department of Chemical Engineering, Federal University of Technology Minna, Niger State, 2002.

[8] A. Adeboye, Production of Adhesive from Cassava starch, B.Sc.Thesis, Department of Chemical Engineering, Federal University of Technology Minna, Niger State, 2003.

[9] D.W. Fuerstenau, J.M. Rosenbaum, J. Laskowski, Effect of surface functional groups on the flotation of coal, Colloids and Surfaces. 8(2) (1983) 153-173.

[10] R.R. Dash, C. Ba lomajumder, A. Kumar, Removal of cyanide from water and wastewater using granular activated carbon, Chemical Engineering Journal, 146 (2009) 408-413.

[11] S.V. Mohan, J. Karthikeyan, Removal of lignin and tannin aqueous solution by adsorption onto activated charcoal, Environmental Pollution. 97 (1997) 183-197.

[12] U. Garg, M.P. Kaur, G.K. Jawa, D. Sud, V.K. Garg, Removal of cadmium(II) from aqueous solutions by adsorption on agricultural waste biomass, Journal of hazardous materials. 154 (2008) 1149-1157.

[13] C.I.A. Nwoko, J.N. Okoji, A.A Ayuk, Adsorption Properties of Dextrin onto Modified Coal Surface, International Journal on Recent and Innovation Trends in Computing and Communication. 4 (2016) 516-522.

[14] H. Deveci, E.Y. Yazıcı, I. Alp, T. Uslu, Removal of cyanide from aqueous solutions by plain and metal-impregnated granular activated carbons, International Journal of Mineral Processing. 79 (2006) 198-208.

[15] S.J. Allen, Q. Gan, R. Matthews, P.A. Johnson, Comparison of optimized isotherm models for basic dye adsorption by kudzu, Bio-resource Technology. 8 (2003) 143- 152.

[16] M.M. Dubinin, L.V. Radushkevich, The equation of the characteristic curve of activated charcoal modified activated carbons, Journal of Colloid and Interface Science. 302 (2006) 408-416.

[17] Z. Aksu, T. Kutsal, A bio-separation process for removing lead(II) ions from waste water by using C. vulgaris, Journal of Chemical Technology and Biotechnology. 52 (1991) 109-118. 
[18] A. Akgerman, M. Zardkoohi, Adsorption of phenolic compounds on fly Ash, Journal of Chemical and Engineering Data. 41 (1996) 185-187.

[19] W.T. Tan, S.T. Ool, C.R. Lee, Removal of chromium (VI) from solution by coconut husk and palm processed fibres, Environmental Technology. 14 (1993) 277-282.

[20] Z. Zhang, L. Moghaddam, O. Hara, W.O.S. Doherty, Congo red adsorption by ball-milled sugarcane bags, Journal of Chem. Eng. 178 (2011) 122-128.

[21] S. Dwivedi et al., Screening of native plants and algae growing on fly-ash affected area near National Thermal Power Coperation, Tanda, Uttar Pradesh, India for accumulation of toxic heavy metal, Journal of hazardous material. 158 (2008) 359-365.

[22] P. Bell, BP Statistical Review of world energy, BP London, 2002. 